\title{
Left Atrial Appendage Thrombus Formation Despite Continuous Non-Vitamin K Antagonist Oral Anticoagulant Therapy in Atrial Fibrillation Patients Undergoing Electrical Cardioversion or Catheter Ablation: A Comparison of Dabigatran and Rivaroxaban
}

\author{
Iwona Gorczyca $\mathbb{D}^{\mathrm{D}}{ }^{1,2}$ Magdalena Chrapek, ${ }^{3}$ Olga Jelonek, ${ }^{2}$ Anna Michalska, \\ Agnieszka Kapłon-Cieślicka, ${ }^{4}$ Beata Uziębło-Życzkowska, ${ }^{5}$ Monika Budnik, \\ Monika Gawałko, ${ }^{4}$ Paweł Krzesiński, ${ }^{5}$ Agnieszka Jurek, ${ }^{5}$ Piotr Scisło, ${ }^{4}$ \\ Janusz Kochanowski, ${ }^{4}$ Marek Kiliszek, ${ }^{5}$ Grzegorz Gielerak, ${ }^{5}$ Krzysztof J. Filipiak, \\ Grzegorz Opolski, ${ }^{4}$ and Beata Wożakowska-Kapłon ${ }^{1,2}$ \\ ${ }^{1}$ Collegium Medicum, The Jan Kochanowski University, Kielce 25-369, Poland \\ ${ }^{2} 1^{\text {st }}$ Clinic of Cardiology and Electrotherapy, Swietokrzyskie Cardiology Centre, Kielce 25-736, Poland \\ ${ }^{3}$ Faculty of Natural Sciences, The Jan Kochanowski University, Kielce 25-369, Poland \\ ${ }^{4} 1$ st Chair and Department of Cardiology, Medical University of Warsaw, Warsaw 02-097, Poland \\ ${ }^{5}$ Department of Cardiology and Internal Diseases, Military Institute of Medicine, Warsaw 04-141, Poland \\ Correspondence should be addressed to Iwona Gorczyca; iwona.gorczyca@interia.pl
}

Received 12 July 2020; Revised 23 August 2020; Accepted 25 August 2020; Published 17 September 2020

Academic Editor: Somasundaram Raghavan

Copyright (c) 2020 Iwona Gorczyca et al. This is an open access article distributed under the Creative Commons Attribution License, which permits unrestricted use, distribution, and reproduction in any medium, provided the original work is properly cited.

\begin{abstract}
Left atrial appendage thrombus (LAAT) may be detected by transesophageal echocardiography (TOE) in patients with atrial fibrillation (AF) despite continuous anticoagulation therapy. We examined the factors predisposing to LAAT in patients treated with the anticoagulants dabigatran and rivaroxaban. We retrospectively evaluated 1,256 AF patients from three centres who underwent TOE before electrical cardioversion $(n=611,51.4 \%)$ or catheter ablation $(n=645,48.6 \%)$ from January 2013 to December 2019 and had been on at least three weeks of continuous dabigatran $(n=603,48 \%)$ or rivaroxaban $(n=653,52 \%)$ therapy. Preprocedural TOE diagnosed LAAT in 51 patients (4.1\%), including 30 patients (5\%) treated with dabigatran and 21 patients $(3.2 \%)$ treated with rivaroxaban $(p=0.1145)$. In multivariate logistic regression, predictors of LAAT in patients treated with dabigatran were non-paroxysmal $\mathrm{AF}$ (vs. paroxysmal $\mathrm{AF})(\mathrm{OR}=6.2, p=0.015)$, heart failure $(\mathrm{OR}=3.22, p=0.003)$, and a eGFR $<60 \mathrm{ml} / \mathrm{min} / 1.73 \mathrm{~m}^{2}(\mathrm{OR}=2.65, p=0.012)$; the predictors in patients treated with rivaroxaban were non-paroxysmal AF (vs. paroxysmal AF) $(\mathrm{OR}=5.73, p=0.0221)$ and heart failure $(\mathrm{OR}=3.19, p=0.116)$. In $\mathrm{ROC}$ analysis of the dabigatran group, the area under the curve (AUC) for the $\mathrm{CHA}_{2} \mathrm{DS}_{2}$-VASc-RAF score was significantly higher (0.78) than those for the CHADS $\mathrm{CHA}_{2} \mathrm{DS}_{2}-\mathrm{VASc}$, and $\mathrm{R}_{2} \mathrm{CHADS}_{2}$ scores $\left(0.67,0.70\right.$, and 0.72 , respectively). In the rivaroxaban group, the $\mathrm{CHA}_{2} \mathrm{DS}_{2}-\mathrm{VASc}-\mathrm{RAF}$ score also performed significantly better (AUC of 0.77) than the CHADS, $\mathrm{CHA}_{2} \mathrm{DS}_{2}$-VASc, and $\mathrm{R}_{2} \mathrm{CHADS}_{2}$ scores (AUC of 0.66 , 0.64 , and 0.67 , respectively). The risk of LAAT was the same for patients in both treatment groups. In all patients, non-paroxysmal $\mathrm{AF}$ or heart failure, and in patients treated with dabigatran an $\mathrm{eGFR}<60 \mathrm{ml} / \mathrm{min} / 1.73 \mathrm{~m}^{2}$, were independent predictors of LAAT. The new $\mathrm{CHA}_{2} \mathrm{DS}_{2}$-VASc-RAF scale had the highest predictive value for LAAT in the entire study population.
\end{abstract}




\section{Introduction}

Risk factors for thromboembolic complications in patients with atrial fibrillation (AF) are well established [1]. Stroke, however, may result from different mechanisms, such as left atrial appendage thrombus (LAAT) embolisation-the risk factors for which are poorly understood and are not necessarily the same as those for stroke in AF patients [2].

According to applicable guidelines, preoperative oral anticoagulant (OAC) therapy is recommended for a minimum of three weeks to prevent periprocedural thromboembolism in AF patients scheduled for elective electrical cardioversion or catheter ablation; alternatively, transoesophageal echocardiography (TOE) may be used to exclude LAAT before the procedure [3]. OAC therapy reduced the periprocedural stroke and systemic embolism risk from $3.4 \%$ to $<1 \%[4,5]$. Some patients had LAAT despite optimal anticoagulation therapy, but this did not necessarily explain the development of thromboembolism in AF patients. Many studies show that the frequency of LAAT in patients with AF varies depending on type and duration of anticoagulation therapy, type of AF, echocardiographic parameters, and concomitant diseases [6-9].

The non-vitamin $\mathrm{K}$ antagonist oral anticoagulants (NOAC) group includes the direct thrombin inhibitor dabigatran and the direct factor $\mathrm{Xa}$ (FXa) inhibitors apixaban, edoxaban, and rivaroxaban. These were approved for AF patients before electrical cardioversion and catheter ablation. The NOACs vary with respect to their mechanism of action, pharmacokinetics, and dosing; so, it is possible that their efficacies in LAAT prevention will differ [10].

Routine periprocedural assessment of NOAC compliance may be problematic because regular laboratory monitoring is not required; therefore, the routine use of TOE prior to cardioversion is discussed extensively.

We examined the effect of specific NOACs on the rates of LAAT and assessed the LAAT predictors in AF patients who had been on continuous anticoagulation therapy prior to electrical cardioversion or catheter ablation.

\section{Materials and Methods}

2.1. Study Design and Participants. We retrospectively evaluated 1,312 AF patients from three centres who underwent TOE before electrical cardioversion or catheter ablation from January 2013 to December 2019 and had been on at least three weeks of continuous NOAC therapy. Patients on apixaban $(n=56)$ were excluded from the study due to low numbers in this category. The final study population consisted of 1,256 patients.

Exclusion criteria were the presence of moderate or severe mitral valve stenosis or a mechanical heart valve.

Research protocol and retrospective review of medical records were approved by the ethics committees of each institution. As this was an observational, retrospective study, the ethics committees waived the requirement of obtaining informed consent from the patients.

All clinical, laboratory, and echocardiographic (including TOE) data were obtained retrospectively from medical records. Patients were divided into three groups according to the AF type (paroxysmal, persistent, and permanent AF), based on a thorough analysis of all available medical records. Patients were classified as having permanent AF after unsuccessful cardioversion during index hospitalisation, or if after receiving a previous diagnosis of permanent AF, their diagnosis was changed to long-standing persistent AF prior to electrical cardioversion or catheter ablation; these patients were classified as permanent AF to distinguish them from persistent AF patients with a presumably lower AF burden.

Vascular disease was defined as prior myocardial infarction, aortic plaque, or peripheral arterial disease.

The estimated glomerular filtration rate (eGFR) used to assess patients' kidney function was calculated using the Modification of Diet in Renal Disease Studyequation.

2.2. Evaluation of Thromboembolic Risk. The $\mathrm{CHADS}_{2}$, $\mathrm{CHA}_{2} \mathrm{DS}_{2}$-VASc, $\mathrm{R}_{2} \mathrm{CHADS}_{2}$, and $\mathrm{CHA}_{2} \mathrm{DS}_{2}$-VASc-RAF scales were used to estimate the risk of thromboembolic events in AF patients [11-14]. The $\mathrm{CHA}_{2} \mathrm{DS}_{2}$-VASc-RAF scale adds AF type and kidney function to the risk assessment according to the $\mathrm{CHA}_{2} \mathrm{DS}_{2}$-VASc scale. All scales used to estimate the risk of thromboembolic complications in $\mathrm{AF}$ patients are listed in Table $1.34 .5 \%$ of patients in the presented study was included in the Kapłon-Cieślicka [14] study upon which the $\mathrm{CHA}_{2} \mathrm{DS}_{2}$-VASc-RAF scale is based.

2.3. Management of Anticoagulation Therapy. All patients received continuous NOAC therapy (dabigatran or rivaroxaban) for at least three weeks before the TOE, including the day of the TOE. NOACs were dosed according to the manufacturer's recommendations.

2.4. Echocardiographic Evaluation. All TOE examinations were conducted within the 48 hours preceding the scheduled electrical cardioversion or catheter ablation procedures and were performed by certified echocardiographers (seconddegree accreditation in echocardiography of the Section of Echocardiography of the Polish Cardiac Society (PCS)), using the General Electric Vivid 7 or E95 ultrasound system (General Electric, Milwaukee, WI), the EPIQ 7 ultrasound machine (Philips Medical Systems, Andover, MA), or the iE33 ultrasound machine (Philips Medical Systems) with the X72 t TOE ultrasound transducer (Philips Medical Systems).

LAAT was defined as an independently mobile echodense structure, distinct from the surrounding endocardium or pectinate muscles, and detected in more than one imaging plane. Dense spontaneous echocontrast (SEC) was defined as a dynamic "smoke-like" signal with a characteristic swirling motion or a dynamic gelatinous, precipitous echodensity without a discrete mass, present throughout the cardiac cycle.

When LAAT was suspected, the images were evaluated by two echocardiographers, and in some cases by a third echocardiographer, to establish an unanimous diagnosis and enable safe referral for electrical cardioversion or catheter 
TABLE 1: Scales applied to estimate the risk of thromboembolic complications in patients with AF.

\begin{tabular}{|c|c|c|c|c|}
\hline \multirow[b]{2}{*}{ Risk factors } & \multicolumn{4}{|c|}{ Scales } \\
\hline & $\begin{array}{c}\mathrm{CHADS}_{2}(\text { maximum } \\
\text { score 6) }\end{array}$ & $\begin{array}{c}\mathrm{R}_{2} \mathrm{CHADS}_{2}(\text { maximum } \\
\text { score } 8 \text { ) }\end{array}$ & $\begin{array}{c}\mathrm{CHA}_{2} \mathrm{DS}_{2}-\mathrm{VASc} \\
\text { (maximum score 9) }\end{array}$ & $\begin{array}{l}\mathrm{CHA}_{2} \mathrm{DS}_{2}-\mathrm{VASc}-\mathrm{RAF} \\
\text { (maximum score } 21 \text { ) }\end{array}$ \\
\hline Congestive heart failure & 1 & 1 & 1 & 1 \\
\hline Hypertension & 1 & 1 & 1 & 1 \\
\hline Diabetes mellitus & 1 & 1 & 1 & 1 \\
\hline Vascular disease & - & - & 1 & 1 \\
\hline Age $65-74$ years & - & - & 1 & 1 \\
\hline $\begin{array}{l}\text { Stroke or transient } \\
\text { ischaemic attack }\end{array}$ & 2 & 2 & 2 & 2 \\
\hline Age $\geq 75$ years & 1 & 1 & 2 & 2 \\
\hline Female sex & - & - & 1 & 1 \\
\hline $\begin{array}{l}\text { Creatinine clearance } \\
<60 \mathrm{~mL} / \mathrm{min}\end{array}$ & - & 2 & - & - \\
\hline $\begin{array}{l}\mathrm{eGFR}<56 \mathrm{~mL} / \mathrm{min} / \\
1.73 \mathrm{~m}^{2}\end{array}$ & - & - & - & 2 \\
\hline Persistent AF & - & - & - & 4 \\
\hline Permanent AF & - & - & - & 10 \\
\hline \multicolumn{5}{|l|}{ Risk categories } \\
\hline Low & 0 & 0 & $\begin{array}{l}0 \text { points in men, } \\
1 \text { point in women }\end{array}$ & $\begin{array}{l}0-4 \text { points in men, } \\
1-5 \text { points in women }\end{array}$ \\
\hline Intermediate & 1 & 1 & $\begin{array}{c}1 \text { point in men, } \\
2 \text { points in women }\end{array}$ & - \\
\hline High & 2 & 2 & $\begin{array}{l}\geq 2 \text { points in men, } \\
\geq 3 \text { points in women }\end{array}$ & $\begin{array}{l}\geq 5 \text { points in men, } \\
\geq 6 \text { points in women }\end{array}$ \\
\hline
\end{tabular}

$\mathrm{AF}$, atrial fibrillation; eGFR, estimated glomerular filtration rate.

ablation. Written informed consent for TOE was obtained from all patients.

In cases with confirmed LAAT, a decision against reversal of sinus rhythm was stated. Further procedures for these patients were decided upon individually.

2.5. Study Endpoint. The study endpoint was the presence of LAAT on TOE.

2.6. Statistical Analysis. Continuous data were described by means, standard deviations, medians, and interquartile range (IQR). Categorical data were summarized by frequencies and percentages. Group comparisons were performed using the chi-squared or Fisher exact test for categorical variables, the $t$-test for continuous, normally distributed variables, or the Mann-Whitney test for continuous, nonnormally variables (normality of distribution was checked with the Shapiro-Wilk test).

The LAAT occurrence was modelled by univariable and multivariable logistic regression in which the odds ratios $(\mathrm{OR})$ and $95 \%$ confidence intervals $(95 \%$ CI $)$ were calculated.

The ability of predicting LAAT occurrence by $\mathrm{CHADS}_{2}$, $\mathrm{CHA}_{2} \mathrm{DS}_{2}$-VASc, $\mathrm{CHA}_{2} \mathrm{DS}_{2}$-VASc-RAF, and $\mathrm{R}_{2} \mathrm{CHADS}_{2}$ scoring systems was assessed by creating receiver operating characteristic (ROC) curves and area under the ROC curve (AUC). The optimal cutoff values were determined by maximising the Youden index. Sensitivity, specificity, and accuracy related to these cutoff values were also calculated, and comparison of ROC curves was performed by DeLong's test.

A two-tailed $p$ value $<0.05$ was considered statistically significant. All statistical analyses were performed using the $R$ software package version 3.6.2.

\section{Results and Discussion}

3.1. Characteristics of the Study Group. This study included 1,256 patients (61.9\% male, mean age 62 years) referred to our centres for catheter ablation $(n=645,48.6 \%)$ or electrical cardioversion $(n=611,51.4 \%)$ of AF. All patients were on NOAC therapy: 603 patients (48\%) on dabigatran and 653 patients $(52 \%)$ on rivaroxaban. A reduced NOAC dose was taken by 110 patients (8.8\%), 52 patients $(8.6 \%)$ treated with dabigatran and 58 patients $(8.9 \%)$ treated with rivaroxaban $(p=0.8714)$. A comparison of baseline characteristics between patients treated with dabigatran and rivaroxaban is presented in Table 2.

According to the $\mathrm{CHA}_{2} \mathrm{DS}_{2}$-VASc scale, 841 patients (67\%) had a high risk of thromboembolic events: 418 patients treated with dabigatran $(69.3 \%)$ and 423 patients (64.8\%) treated with rivaroxaban $(p=0.1947)$. According to the HASBLED scale, 152 patients (12.1\%) had a high risk of haemorrhagic complications: 83 patients (13.8\%) treated with dabigatran and 69 patients (10.6\%) treated with rivaroxaban $(p=0.0826)$. 
TABLE 2: Baseline characteristics of patient study groups.

\begin{tabular}{|c|c|c|c|c|}
\hline Variable & $\begin{array}{l}\text { All patients } \\
(n=1256)\end{array}$ & $\begin{array}{l}\text { Patients treated with dabigatran } \\
\qquad(n=603)\end{array}$ & $\begin{array}{l}\text { Patients treated with rivaroxaban } \\
\qquad(n=653)\end{array}$ & $p$ \\
\hline Female, $n(\%)$ & $479(38.1)$ & $215(35.7)$ & $264(40.4)$ & 0.0818 \\
\hline Age, mean \pm SD & $62.5 \pm 11.4$ & $62.2 \pm 11.3$ & $62.7 \pm 11.6$ & \\
\hline Median (IQR), years & $64.0(57.0,70.0)$ & $63.0(56.0,69.0)$ & $64.0(57.0,70.0)$ & 0.3245 \\
\hline \multicolumn{5}{|l|}{ Clinical characteristics, $n(\%)$} \\
\hline Heart failure & $263(20.9)$ & $131(21.7)$ & $132(20.2)$ & 0.5110 \\
\hline Hypertension & $911(72.5)$ & $438(72.6)$ & $473(72.4)$ & 0.9362 \\
\hline Diabetes mellitus & $231(18.4)$ & $119(19.7)$ & $112(17.2)$ & 0.2378 \\
\hline Stroke/TIA/peripheral thrombus & $93(7.4)$ & $51(8.5)$ & $42(6.4)$ & 0.1707 \\
\hline Vascular disease & $254(20.2)$ & $128(21.2)$ & $126(19.3)$ & 0.3945 \\
\hline \multicolumn{5}{|l|}{ AF type } \\
\hline Paroxysmal & $517(41.2)$ & $229(38.0)$ & $288(44.1)$ & \\
\hline Persistent & $674(53.7)$ & $336(55.7)$ & $338(51.8)$ & 0.0365 \\
\hline Permanent & $65(5.2)$ & $38(6.3)$ & $27(4.1)$ & \\
\hline Non-paroxysmal & $739(58.8)$ & $374(62.0)$ & $365(55.9)$ & 0.0275 \\
\hline \multicolumn{5}{|l|}{ Thromboembolism risk } \\
\hline $\mathrm{CHADS}_{2}$, mean $\pm \mathrm{SD}$ & $1.4 \pm 1.1$ & $1.4 \pm 1.1$ & $1.4 \pm 1.1$ & \\
\hline Median (IQR) & $1.0(1.0,2.0)$ & $1.0(1.0,2.0)$ & $1.0(1.0,2.0)$ & 0.7413 \\
\hline $\mathrm{CHADS}_{2}=0, n(\%)$ & $247(19.7)$ & $119(19.7)$ & $128(19.6)$ & 0.7413 \\
\hline $\mathrm{CHADS}_{2}=1, n(\%)$ & $536(42.7)$ & $251(41.6)$ & $285(43.6)$ & \\
\hline $\mathrm{CHADS}_{2} \geq 2, n(\%)$ & $473(37.7)$ & $233(38.6)$ & $240(36.8)$ & \\
\hline $\mathrm{CHA}_{2} \mathrm{DS}_{2}-\mathrm{VASc}$, mean $\pm \mathrm{SD}$ & $2.4 \pm 1.7$ & $2.5 \pm 1.7$ & $2.4 \pm 1.6$ & 0.9358 \\
\hline Median (IQR) & $2.0(1.0,3.0)$ & $2.0(1.0,3.0)$ & $2.0(1.0,3.0)$ & \\
\hline $\mathrm{CHA}_{2} \mathrm{DS}_{2}-\mathrm{VASc}=0, n(\%)$ & $135(10.7)$ & $63(9.6)$ & $72(11.9)$ & 0.1947 \\
\hline $\mathrm{CHA}_{2} \mathrm{DS}_{2}-\mathrm{VASc}=1, n(\%)$ & $280(22.3)$ & $122(20.2)$ & $158(24.2)$ & \\
\hline $\mathrm{CHA}_{2} \mathrm{DS}_{2}-\mathrm{VASc} \geq 2, n(\%)$ & $841(67)$ & $418(69.3)$ & $423(64.8)$ & \\
\hline $\mathrm{CHA}_{2} \mathrm{DS}_{2}-\mathrm{VASc}-\mathrm{RAF}$ mean $\pm \mathrm{SD}$ & $5.5 \pm 3.6$ & $5.7 \pm 3.6$ & $5.3 \pm 3.6$ & \\
\hline Median (IQR) & $5.0(3.0,8.0)$ & $6.0(3.0,8.0)$ & $5.0(2.0,7.0)$ & 0.0351 \\
\hline $\mathrm{R}_{2} \mathrm{CHADS}_{2}$, mean $\pm \mathrm{SD}$ & $2.0 \pm 1.5$ & $2.0 \pm 1.6$ & $1.9 \pm 1.5$ & \\
\hline Median (IQR) & $2.0(1.0,3.0)$ & $2.0(1.0,3.0)$ & $1.0(1.0,3.0)$ & 0.2755 \\
\hline \multicolumn{5}{|l|}{ Bleeding risk } \\
\hline HASBLED, mean \pm SD & $1.4 \pm 0.9$ & $1.4 \pm 1.0$ & $1.4 \pm 0.9$ & \\
\hline Median (IQR) & $1.0(1.0,2.0)$ & $1.0(1.0,2.0)$ & $1.0(1.0,2.0)$ & 0.9782 \\
\hline HASBLED $<3$ & $1104(87.9)$ & $520(86.2)$ & $584(89.4)$ & 0.0826 \\
\hline \multicolumn{5}{|l|}{ Laboratory tests } \\
\hline $\mathrm{HGB}$, mean $\pm \mathrm{SD}$ & $n=1229$ & $n=589$ & $n=640$ & \\
\hline & $14.2 \pm 1.5$ & $14.2 \pm 1.6$ & $14.2 \pm 1.5$ & 0.9563 \\
\hline Median (IQR) & $14.2(13.2,15.2)$ & $14.2(13.2,15.2)$ & $14.2(13.3,15.1)$ & \\
\hline & $n=1225$ & $n=586$ & $n=639$ & \\
\hline $\mathrm{PLT}$, mean $\pm \mathrm{SD}$ & $221.5 \pm 62.0$ & $217.6 \pm 59.6$ & $225.1 \pm 64.1$ & 0.0150 \\
\hline Median (IQR) & $217.0(179.0,253.0)$ & $210.5(178.0,248.8)$ & $222.0(180.0,258.0)$ & \\
\hline Creatinine, mean $\pm \mathrm{SD}$ & $1.1 \pm 0.3$ & $1.1 \pm 0.3$ & $1.1 \pm 0.3$ & \\
\hline Median (IQR) & $1.0(0.9,1.2)$ & $1.1(0.9,1.2)$ & $1.0(0.9,1.2)$ & 0.0324 \\
\hline $\mathrm{eGFR}$, mean $\pm \mathrm{SD}$ & $72.2 \pm 17.9$ & $70.9 \pm 17.0$ & $73.5 \pm 18.6$ & \\
\hline Median (IQR) & $72.0(58.2,90.0)$ & $70.3(58.0,87.1)$ & $74.5(58.5,90.0)$ & 0.0031 \\
\hline $\mathrm{eGFR}<60 \mathrm{ml} / \mathrm{min} / 1.73 \mathrm{~m}^{2}$ & $359(28.6)$ & $175(29.0)$ & $184(28.2)$ & 0.7409 \\
\hline \multicolumn{5}{|l|}{ Echocardiographic findings } \\
\hline \multirow{3}{*}{$\begin{array}{l}\mathrm{LA}, \text { mean } \pm \mathrm{SD} \\
\text { Median (IQR), mm }\end{array}$} & $n=516$ & $n=263$ & $n=253$ & \\
\hline & $44.9 \pm 5.7$ & $45.6 \pm 5.8$ & $44.3 \pm 5.6$ & 0.0124 \\
\hline & $45.0(41.0,48.0)$ & $45.0(42.0,49.0)$ & $44.0(41.0,48.0)$ & \\
\hline \multirow{3}{*}{$\begin{array}{l}\text { LVDD, mean } \pm \text { SD } \\
\text { Median (IQR), mm }\end{array}$} & $n=412$ & $n=219$ & $n=193$ & \\
\hline & $51.7 \pm 6.4$ & $52.7 \pm 6.4$ & $50.6 \pm 6.2$ & 0.0007 \\
\hline & $51.0(47.0,55.2)$ & $53.0(48.0,56.0)$ & $50.0(46.0,54.0)$ & \\
\hline \multirow{3}{*}{$\begin{array}{l}\text { LVEF, mean } \pm \text { SD } \\
\text { Median (IQR), \% }\end{array}$} & $n=616$ & $n=291$ & $n=325$ & \\
\hline & $54.4 \pm 9.6$ & $53.6 \pm 10.0$ & $55.1 \pm 9.2$ & 0.0563 \\
\hline & $58.0(50.0,60)$ & $55.0(50.0,60)$ & $58.0(50.0,60)$ & \\
\hline \multirow{3}{*}{$\begin{array}{l}\text { LAAV, mean } \pm \text { SD median (IQR), } \\
\mathrm{cm} / \mathrm{sec}\end{array}$} & $n=769$ & $n=319$ & $n=450$ & \\
\hline & $0.5 \pm 0.3$ & $0.5 \pm 0.3$ & $0.5 \pm 0.3$ & 0.0062 \\
\hline & $0.4(0.3,0.7)$ & $0.5(0.3,0.7)$ & $0.4(0.3,0.6)$ & \\
\hline \multicolumn{5}{|l|}{ Study endpoint } \\
\hline LAAT, $n(\%)$ & $51(4.1)$ & $30(5.0)$ & $21(3.2)$ & 0.1145 \\
\hline
\end{tabular}

AF, atrial fibrillation; eGFR, estimated glomerular filtration rate; HGB, hemoglobin; LA, left atrial; LAAT, left atrial appendage thrombus; LAAV, left atrial appendage peak emptying velocity; LVEF, left ventricular ejection fraction; LVDD, left ventricular diastolic dimension; PLT, platelets; SD, standard deviation; SEC, spontaneous echocardiographic contrast; TIA, transient ischaemic attack. 
3.2. Prevalence of LAAT and SEC Detection by TOE. LAAT formation was found in 51 patients (4.1\%), and there was no significant difference in incidence between patients treated with dabigatran vs. rivaroxaban $(5 \%$ vs. $3.2 \%$, $p=0.1145$ ) (Table 2). The incidence of SEC was lower in patients treated with dabigatran vs. rivaroxaban $(12.6 \%$ vs. $18.8 \%, p=0.0025)$.

3.3. Analysis of Factors Predisposing to Thrombosis. In patients treated with dabigatran, those with LAAT were older than patients without LAAT, were more likely to be diabetic, had a higher HASBLED score, and had a lower GFR. Patients with LAAT-irrespective of which NOAC treatment they were on-were more likely to have heart failure, non-paroxysmal AF, and higher $\mathrm{CHADS}_{2}, \mathrm{CHA}_{2} \mathrm{DS}_{2}$-VASc, $\mathrm{CHA}_{2} \mathrm{DS}_{2}$-VASc-RAF, and $\mathrm{R}_{2} \mathrm{CHADS}$ scores than patients without LAAT (Table 2). Reduced doses of dabigatran and rivaroxaban yielded similar results in patients with and without LAAT (Table 3).

In multivariate logistic regression, predictors of LAAT in patients treated with dabigatran were heart failure, non-paroxysmal AF (vs paroxysmal AF), and an eGFR $<60 \mathrm{ml} / \mathrm{min} / 1.73 \mathrm{~m}^{2}$, as given in Table 4; predictors of LAAT in patients treated with rivaroxaban were heart failure and non-paroxysmal AF (vs paroxysmal AF), as given in Table 5.

3.4. Assessment of the Predictive Value of Selected Scales. ROC curves corresponding to the discriminant capacity of selected scales indicated that the $\mathrm{CHA}_{2} \mathrm{DS}_{2}$-VASc-RAF scale had better predictive ability for LAAT than any of the other presented scales in both the dabigatran and rivaroxaban treatment groups (Figures 1 and 2).

Based on the Youden index, the optimal cutoffs for the $\mathrm{CHADS}_{2}, \mathrm{CHA}_{2} \mathrm{DS}_{2}$-VASc, $\mathrm{CHA}_{2} \mathrm{DS}_{2}$-VASc-RAF, and $\mathrm{R}_{2}$ CHADS scores to predict LAAT are 2 points, 3 points, 7 points, and 3 points, respectively (Figures 1 and 2). The results are the same for each treatment group.

In the group of patients treated with dabigatran, the $\mathrm{CHA}_{2} \mathrm{DS}_{2}$-VASc-RAF score showed statistically significant higher ability to differentiate between patients with LAAT and without LAAT compared to the $\mathrm{CHA}_{2} \mathrm{DS}_{2}$-VASc score $(p=0.0189)$ and $\mathrm{CHADS}_{2}(p=0.0036)$ score, whereas the difference compared to the $\mathrm{R}_{2} \mathrm{CHADS}_{2}$ score $(p=0.0875)$ was statistically insignificant ( $p=0.0875)$.

Similarly, in the group of patients treated with rivaroxaban, the $\mathrm{CHA}_{2} \mathrm{DS}_{2}$-VASc-RAF score showed statistically significant higher ability to differentiate between patients with LAAT and without LAAT compared to the $\mathrm{CHA}_{2} \mathrm{DS}_{2}$ VASc score $(p=0.0071)$ and $\mathrm{CHADS}_{2}$ score $(p=0.0498)$, whereas the difference compared to the $\mathrm{R}_{2} \mathrm{CHADS}_{2}$ score was statistically indifferent $(p=0.07)$.

Both in the cases of patients treated with dabigatran and with rivaroxaban, the differences between remaining pairs of scores in terms of differentiating between LAAT presence and its lack were not statistically significant $(p>0.05)$.

\section{Discussion}

The risk for LAAT is similar in patients treated with dabigatran and rivaroxaban, irrespective of the dose. In both treatment groups, heart failure and non-paroxysmal AF (vs paroxysmal AF) proved to be strong predictors of LAAT. Impaired renal function was a predictor of LAAT only in patients treated with dabigatran.

Despite continuous NOAC treatment, $5 \%$ of patients treated with dabigatran and $3.2 \%$ of patients treated with rivaroxaban developed LAAT. The percentage of SEC was statistically lower in patients treated with dabigatran vs. rivaroxaban ( $12.6 \%$ vs. $18.8 \%, p=0.0025)$.

In a group of 611 patients with $\mathrm{AF}$ or atrial flutter before catheter ablation, $\mathrm{Wu}$ et al. showed that the incidence of LAAT was $3 \%$ in patients treated with dabigatran and 3.5\% in patients treated with rivaroxaban [15]. Bertaglia et al. analysed a group of $414 \mathrm{AF}$ patients treated with NOACs prior to electrical cardioversion or catheter ablation and found that LAAT was diagnosed in $3.1 \%$ of those treated with dabigatran and $4.7 \%$ of those treated with rivaroxaban [9]. In the X-VeRT study of patients treated with rivaroxaban, LAAT occurred in $2.7 \%$ of 564 patients who underwent TOE prior to electrical cardioversion of AF [16].

Compared to our study, the frequency of LAAT in the RE-LY trial was lower: $1.8 \%$ in the dabigatran $110 \mathrm{mg}$ BID (twice daily dosing) group and $1.2 \%$ in the dabigatran $150 \mathrm{mg}$ BID group [17]. In the RE-LY study, a low percentage of patients underwent TOE before electrical cardioversion. TOE was conducted for $26 \%$ of patients treated with the reduced dose of dabigatran and $24 \%$ of patients treated with the full dose [17].

In our study, a reduced dose of NOACs was prescribed to $8.6 \%$ of patients treated with dabigatran and $8.9 \%$ of patients treated with rivaroxaban. A reduced NOAC dose was not a predictor of LAAT in patients treated with dabigatran or rivaroxaban. Similarly, Gawalko et al. [18] reported that prior to cardioversion or catheter ablation, $8 \%$ of patients treated with dabigatran and $11 \%$ of patients treated with rivaroxaban were prescribed reduced doses and did not show an increased risk of LAAT. In our study, $26 \%$ of patients constituted those from the study of Gawalko et al. [18]. A meta-analysis by Reers et al. [6] showed that the approximately $5 \%$ rate of LAAT formation is considerably higher than the average stroke rate of $<1 \%$. This suggests that not all thrombi present during or after electrical cardioversion cause a cerebral thromboembolic event.

Some studies have found the $\mathrm{CHADS}_{2}$ and $\mathrm{CHA}_{2} \mathrm{DS}_{2}$ VASc scores to be the strongest predictors of LAAT prior to electrical cardioversion [19-21].

In our study, the $\mathrm{CHADS}_{2}$ and $\mathrm{CHA}_{2} \mathrm{DS}_{2}$-VASc scores were statistically higher in patients with LAAT than those without, regardless of whether they were treated with dabigatran or rivaroxaban. In the logistic regression analysis, individual components of the $\mathrm{CHADS}_{2}$ and $\mathrm{CHA}_{2} \mathrm{DS}_{2}$ VASc scales were assessed because different patients with the same score on these scales can each present with a completely different clinical picture. As most components of the $\mathrm{CHADS}_{2}$ and $\mathrm{CHA}_{2} \mathrm{DS}_{2}-\mathrm{VASc}$ scores are risk factors for 
TABLE 3: Comparison of patients with and without left atrial appendage thrombus among patients treated with dabigatran and rivaroxaban.

\begin{tabular}{|c|c|c|c|c|c|c|}
\hline \multirow{2}{*}{ Variable } & \multicolumn{2}{|c|}{ Patients treated with dabigatran $(n=603)$} & \multirow[b]{2}{*}{$p$} & \multicolumn{2}{|c|}{$\begin{array}{l}\text { Patients treated with rivaroxaban } \\
\qquad(n=653)\end{array}$} & \multirow[b]{2}{*}{$p$} \\
\hline & $\begin{array}{l}\text { With LAAT } \\
\quad(n=30)\end{array}$ & $\begin{array}{l}\text { Without LAAT } \\
\quad(n=573)\end{array}$ & & $\begin{array}{l}\text { With LAAT } \\
\quad(n=21)\end{array}$ & $\begin{array}{l}\text { Without LAAT } \\
\quad(n=632)\end{array}$ & \\
\hline Female, $n(\%)$ & $15(50.0)$ & $200(34.9)$ & 0.0924 & $7(33.3)$ & $257(40.7)$ & 0.5006 \\
\hline Age, mean \pm SD & $68.9 \pm 8.6$ & $61.8 \pm 11.3$ & & $67.0 \pm 8.9$ & $62.5 \pm 11.6$ & \\
\hline Median (IQR), years & $68.0(65.0,74.0)$ & $63.0(56.0,69.0)$ & 0.0008 & $70.0(61.0,73.0)$ & $64.0(57.0,70.0)$ & 0.0590 \\
\hline NOAC reduced dose, $n(\%)$ & $5(16.7)$ & $47(8.2)$ & 0.1685 & $56(8.9)$ & $56(8.9)$ & 0.7091 \\
\hline \multicolumn{7}{|l|}{ Clinical characteristics, $n(\%)$} \\
\hline Heart failure & $16(53.3)$ & $115(20.1)$ & $<0.0001$ & $11(52.4)$ & $121(19.1)$ & 0.0009 \\
\hline Hypertension & $22(73.3)$ & $416(72.6)$ & 0.93 & $18(85.7)$ & $455(72.0)$ & 0.1663 \\
\hline Diabetes mellitus & $12(40.0)$ & $107(18.7)$ & 0.042 & $6(28.6)$ & $106(16.8)$ & 0.2325 \\
\hline $\begin{array}{l}\text { Stroke/TIA/embolism } \\
\text { peripheral }\end{array}$ & $3(10.0)$ & $48(8.4)$ & 0.7334 & $2(9.5)$ & $40(6.3)$ & 0.6388 \\
\hline Vascular disease & $10(33.3)$ & $118(20.6)$ & 0.0962 & $5(23.8)$ & $121(19.1)$ & 0.5766 \\
\hline \multicolumn{7}{|l|}{ AF type, $n(\%)$} \\
\hline Paroxysmal & $2(6.7)$ & $227(39.6)$ & & $2(9.5)$ & $286(45.3)$ & \\
\hline Persistent & $21(70.0)$ & $315(55.0)$ & $<0.0001$ & $11(52.4)$ & $327(51.7)$ & $<0.0001$ \\
\hline Permanent & $7(23.3)$ & $7(23.3)$ & & $19(3.0)$ & $8(38.1)$ & \\
\hline Non-paroxysmal & $28(93.3)$ & $346(60.4)$ & 0.0003 & $19(90.5)$ & $346(54.7)$ & 0.0012 \\
\hline \multicolumn{7}{|l|}{ Thromboembolism risk } \\
\hline $\mathrm{CHADS}_{2}$, mean $\pm \mathrm{SD}$ & $2.1 \pm 1.2$ & $1.4 \pm 1.1$ & & $1.9 \pm 1.0$ & $1.3 \pm 1.1$ & \\
\hline $\begin{array}{l}\text { median } \\
\text { (IQR) }\end{array}$ & $2.0(1.0,3.0)$ & $1.0(1.0,2.0)$ & 0.0013 & $2.0(1.0,2.0)$ & $1.0(1.0,2.0)$ & 0.0081 \\
\hline $\mathrm{CHADS}_{2}=0, n(\%)$ & $2(6.7)$ & $117(20.4)$ & & $1(4.8)$ & $127(20.1)$ & \\
\hline $\mathrm{CHADS}_{2}=1, n(\%)$ & $9(30.0)$ & $242(42.2)$ & 0.0127 & $6(28.6)$ & $279(44.1)$ & 0.0165 \\
\hline $\mathrm{CHADS}_{2} \geq 2, n(\%)$ & $19(63.3)$ & $214(37.3)$ & & $14(66.7)$ & $226(35.8)$ & \\
\hline $\mathrm{CHA}_{2} \mathrm{DS}_{2}-\mathrm{VASc}$, mean $\pm \mathrm{SD}$ & $3.7 \pm 1.7$ & $2.4 \pm 1.7$ & & $3.0 \pm 1.4$ & $2.4 \pm 1.6$ & 0.0309 \\
\hline Median (IQR) & $3.5(2.0,5.0)$ & $2.0(1.0,3.0)$ & $<0.0001$ & $3.0(3.0,4.0)$ & $2.0(1.0,3.0)$ & 0.0509 \\
\hline $\mathrm{CHA}_{2} \mathrm{DS}_{2}-\mathrm{VASc}=0, n(\%)$ & $0(0.0)$ & $72(12.6)$ & & $1(4.8)$ & $62(9.8)$ & \\
\hline $\mathrm{CHA}_{2} \mathrm{DS}_{2}-\mathrm{VASc}=1, n(\%)$ & $2(6.7)$ & $120(20.9)$ & 0.0078 & $2(9.5)$ & $156(24.7)$ & 0.2026 \\
\hline $\mathrm{CHA}_{2} \mathrm{DS}_{2}-\mathrm{VASc} \geq 2, n(\%)$ & $28(93.3)$ & $381(66.5)$ & & $18(85.8)$ & $414(65.5)$ & \\
\hline $\mathrm{CHA}_{2} \mathrm{DS}_{2}$-VASc-RAF, & $9.7 \pm 4.1$ & $5.5 \pm 3.5$ & & $9.5 \pm 4.6$ & $5.2 \pm 3.5$ & \\
\hline $\begin{array}{l}\text { mean } \pm \text { SD } \\
\quad \text { Median (IQR) }\end{array}$ & $9.5(7.0,11.8)$ & $5.0(3.0,8.0)$ & $<0.0001$ & $7.0(7.0,13.0)$ & $5.0(2.0,7.0)$ & $<0.0001$ \\
\hline $\mathrm{R}_{2} \mathrm{CHADS}$, mean $\pm \mathrm{SD}$ & $3.2 \pm 1.5$ & $1.9 \pm 1.5$ & $<0.0001$ & $2.8 \pm 1.5$ & $1.9 \pm 1.5$ & 0.0051 \\
\hline Median (IQR), & $3.0(2.0,4.0)$ & $2.0(1.0,3.0)$ & $<0.0001$ & $3.0(2.0,3.0)$ & $1.0(1.0,3.0)$ & \\
\hline \multicolumn{7}{|l|}{ Bleeding risk } \\
\hline HASBLED, mean \pm SD & $1.9 \pm 1.0$ & $1.4 \pm 1.0$ & & $1.9 \pm 1.2$ & $1.4 \pm 0.9$ & \\
\hline Median (IQR) & $2.0(1.0,2.0)$ & $1.0(1.0,2.0)$ & & $2.0(1.0,2.0)$ & $1.0(1.0,2.0)$ & 2 \\
\hline HASBLED $<3$ & $24(80.0)$ & $496(86.6)$ & 0.2833 & $17(81.0)$ & $567(89.7)$ & 0.2645 \\
\hline \multicolumn{7}{|l|}{ Laboratory tests } \\
\hline $\mathrm{eGFR}$, mean $\pm \mathrm{SD}$ & $62.8 \pm 18.9$ & $71.3 \pm 16.9$ & & $69.5 \pm 20.6$ & $73.6 \pm 18.6$ & \\
\hline Median (IQR) & $59.6(50.6,76.6)$ & $70.8(58.3,87.4)$ & & $71.3(52.0,90.0)$ & $74.6(58.9,90.0)$ & \\
\hline $\mathrm{eGFR}<60 \mathrm{ml} / \mathrm{min} / 1.73 \mathrm{~m}^{2}$ & $16(53.3)$ & $159(27.7)$ & 0.0026 & $9(42.9)$ & $175(27.7)$ & 0.1285 \\
\hline
\end{tabular}

AF, atrial fibrillation; eGFR, estimated glomerular filtration rate; LAAT, left atrial appendage thrombus; NOAC, non-vitamin K antagonist oral anticoagulants; SD, standard deviation; TIA, transient ischaemic attack.

TABLE 4: Univariate and multivariate analysis of predictive factors for LAAT in patients treated with dabigatran.

\begin{tabular}{|c|c|c|c|c|c|c|}
\hline \multirow{2}{*}{ Variable } & \multicolumn{3}{|c|}{ Univariate analysis } & \multicolumn{3}{|c|}{ Multivariate analysis } \\
\hline & OR & $95 \% \mathrm{CI}$ & $p$ & OR & $95 \% \mathrm{CI}$ & $p$ \\
\hline Heart failure & 4.55 & $2.16-9.6$ & 0.0001 & 3.22 & $1.50-6.95$ & 0.003 \\
\hline Hypertension & 1.04 & $0.45-2.38$ & 0.93 & & & \\
\hline Age (per 5 years) & 1.40 & $1.15-1.70$ & 0.0009 & & & \\
\hline Diabetes mellitus & 2.90 & $1.36-6.21$ & 0.006 & & & \\
\hline Stroke/TIA/peripheral thrombus & 1.22 & $0.36-4.15$ & 0.7558 & & & \\
\hline Vascular disease & 1.93 & $0.88-4.23$ & 0.1015 & & & \\
\hline Female & 1.86 & $0.89-3.89$ & 0.097 & & & \\
\hline Non-paroxysmal AF & 9.18 & $2.17-3.89$ & 0.0026 & 6.20 & $1.43-26.93$ & 0.015 \\
\hline $\mathrm{eGFR}<60 \mathrm{ml} / \mathrm{min} / 1.73 \mathrm{~m}^{2}$ & 2.98 & $1.42-6.24$ & 0.0039 & 2.65 & $1.24-5.66$ & 0.012 \\
\hline
\end{tabular}

95\% CI, 95\% confidence interval; AF, atrial fibrillation; eGFR, estimated glomerular filtration rate; OR, odds ratio; TIA, transient ischaemic attack. 
TABLE 5: Univariate and multivariate analysis of predictive factors for LAAT in patients treated with rivaroxaban.

\begin{tabular}{|c|c|c|c|c|c|c|}
\hline \multirow{2}{*}{ Variable } & \multicolumn{3}{|c|}{ Univariate analysis } & \multicolumn{3}{|c|}{ Multivariate analysis } \\
\hline & OR & $95 \% \mathrm{CI}$ & $p$ & OR & $95 \% \mathrm{CI}$ & $p$ \\
\hline Heart failure & 4.65 & $1.93-11.19$ & 0.0006 & 3.19 & $1.30-7.85$ & 0.0116 \\
\hline Hypertension & 2.33 & $0.68-8.02$ & 0.1783 & & & \\
\hline Age (per 5 years) & 1.21 & $0.98-1.50$ & 0.0822 & & & \\
\hline Diabetes mellitus & 1.98 & $0.75-5.23$ & 0.1657 & & & \\
\hline Stroke/TIA/peripheral thrombus & 1.56 & $0.35-6.92$ & 0.5603 & & & \\
\hline Vascular disease & 1.32 & $0.47-3.67$ & 0.5953 & & & \\
\hline Female & 0.73 & $0.29-1.83$ & 0.5 & & & \\
\hline Non-paroxysmal AF & 7.85 & $1.81-33.99$ & 0.0058 & 5.73 & $1.29-25.58$ & 0.0221 \\
\hline $\mathrm{eGFR}<60 \mathrm{ml} / \mathrm{min} / 1.73 \mathrm{~m}^{2}$ & 1.96 & $0.81-4.73$ & 0.1351 & & & \\
\hline
\end{tabular}

95\% CI, 95\% confidence interval; AF, atrial fibrillation; eGFR, estimated glomerular filtration rate; OR, odds ratio; TIA, transient ischaemic attack.

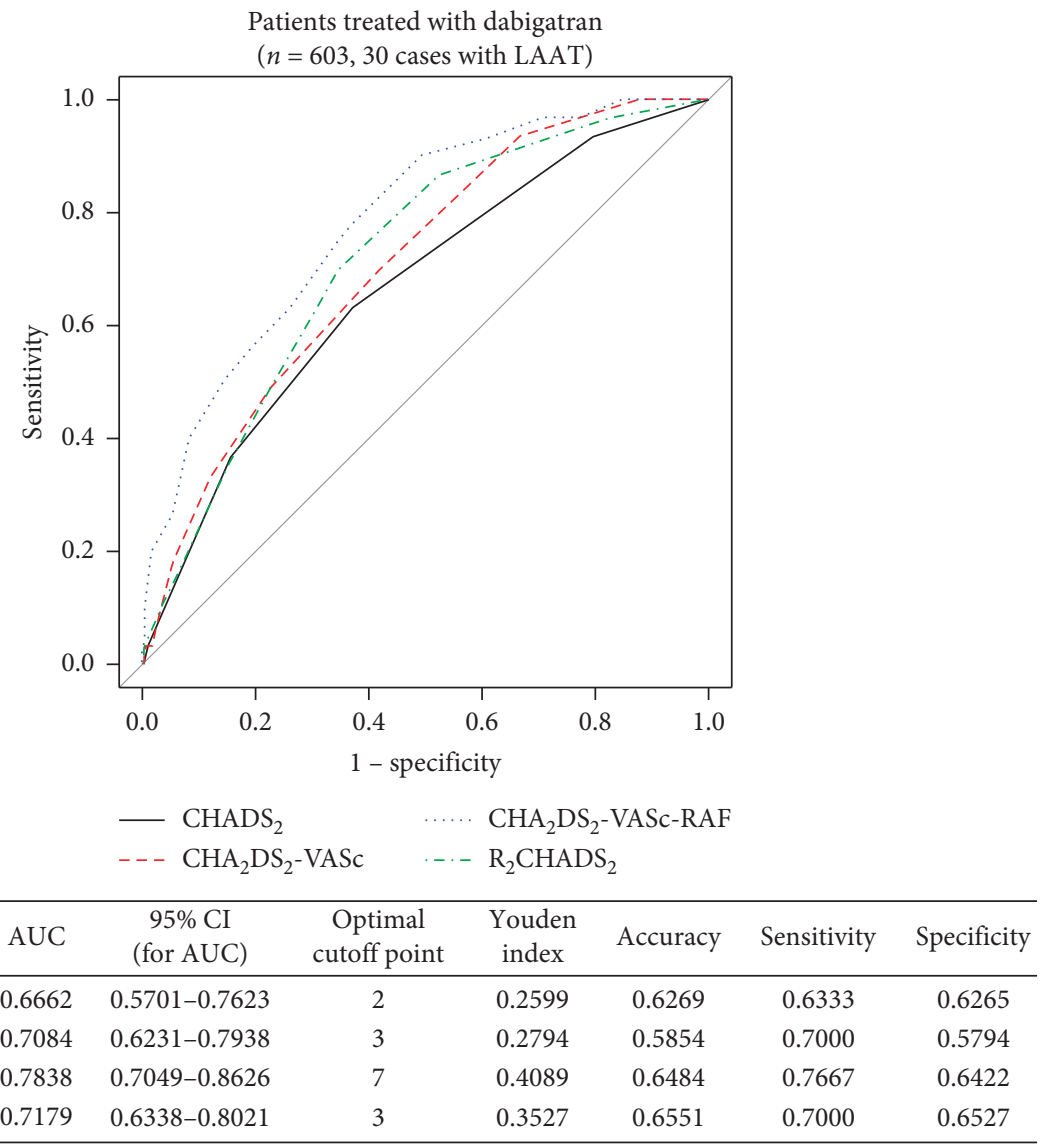

FIGURE 1: Receiver operating curves of $\mathrm{CHADS}_{2}, \mathrm{CHA}_{2} \mathrm{DS}_{2}$-VASc, $\mathrm{CHA}_{2} \mathrm{DS}_{2}$-VASc-RAF, and $\mathrm{R}_{2} \mathrm{CHADS}$, for predicting LAAT and associated characteristics of that prediction in the dabigatran treatment group.

atherosclerosis, the atherothrombotic mechanism may explain the positive association of $\mathrm{CHADS}_{2} / \mathrm{CHA}_{2} \mathrm{DS}_{2}$-VASc scores with stroke events in patients with nonvalvular atrial fibrillation (NVAF). In the era of NOACs, Frenkel et al. [22] showed that no patients with a $\mathrm{CHA}_{2} \mathrm{DS}_{2}-\mathrm{VASc}$ score of 0 and normal ejection fraction $(\mathrm{EF})(\geq 55 \%)$ had LAAT. Kawabata et al. [23] also reported that LAAT was absent in patients with a $\mathrm{CHA}_{2} \mathrm{DS}_{2}$-VASc score of 0 or in paroxysmal AF patients without a prior stroke/transient ischaemic attack
(TIA) history. Contrary to the aforementioned studies, our study found LAAT in patients with low risk of thromboembolic complications according to the abovementioned scales. Therefore, it is extremely important to look for factors that predispose to LAAT other than the $\mathrm{CHADS}_{2}$ and $\mathrm{CHA}_{2} \mathrm{DS}_{2}$-VASc scores.

In our study, non-paroxysmal $\mathrm{AF}$ was the strongest independent predictor of LAAT in patients treated with dabigatran and rivaroxaban (OR 6.2 for patients treated with 


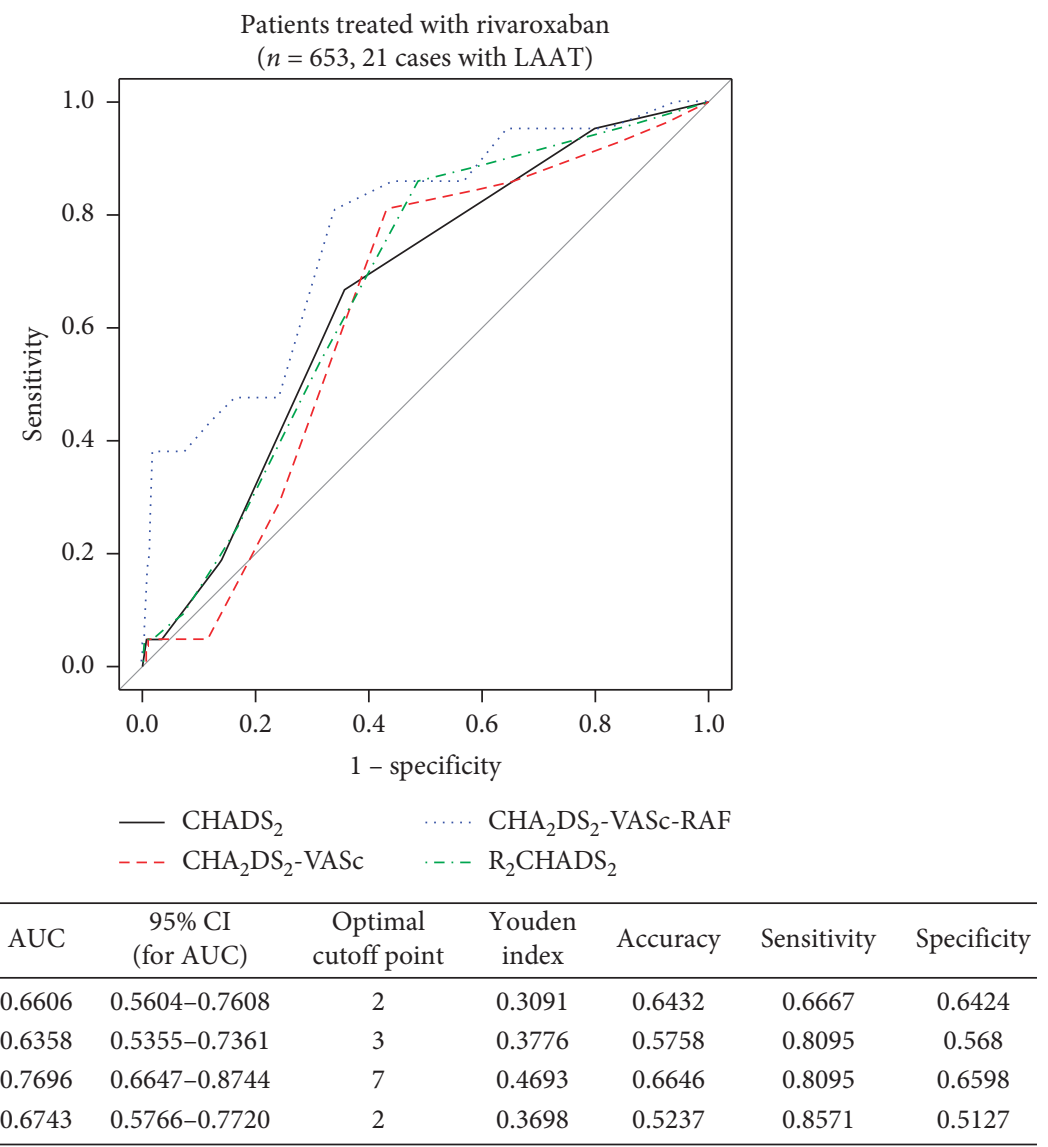

FIgURE 2: Receiver operating curves of $\mathrm{CHADS}_{2}, \mathrm{CHA}_{2} \mathrm{DS}_{2}-\mathrm{VASc}, \mathrm{CHA}_{2} \mathrm{DS}_{2}$-VASc-RAF, and $\mathrm{R}_{2} \mathrm{CHADS}$, for predicting LAAT and associated characteristics of that prediction in the rivaroxaban treatment group.

dabigatran and OR 5.73 for patients treated with rivaroxaban). Data regarding the effect of AF on the incidence of LAAT are inconsistent. The authors of the guidelines of the European Society of Cardiology emphasise that the type of AF does not affect the risk of thromboembolic complications [3]. However, meta-analysis data from 99,969 patients with AF confirmed that the risk of thromboembolic complications in patients with non-paroxysmal AF is $38 \%$ higher than in patients with paroxysmal AF [24]. There may occur as various mechanisms by which non-paroxysmal AF carries a higher thromboembolic risk than paroxysmal $\mathrm{AF}$, including changes in $\mathrm{LA}$ wall structure, longer periods of LAA/LA stunning, or other cardiovascular abnormalities promoting thromboembolism.

Heart failure is a recognized risk factor for thromboembolic complications in patients with AF. Univariate analysis within our study determined that heart failure was the strongest of all the $\mathrm{CHA}_{2} \mathrm{DS}_{2}$-VASc scale components as a predictor of LAAT in all patients, which was confirmed by multivariate analysis. It was also among the most powerful determinants of LAAT in a meta-analysis including 20,516 AF patients [25].

Impaired renal function is a recognized risk factor for thromboembolic complications. In the patients treated with dabigatran, an eGFR $<60 \mathrm{ml} / \mathrm{min} / 1.73 \mathrm{~m}^{2}$ was predictive for LAAT. This is clinically relevant because the patient characteristics and the percentage of patients with eGFR $<60 \mathrm{ml} /$ $\mathrm{min} / 1.73 \mathrm{~m}^{2}$ in both NOAC treatment groups were similar. The meta-analysis including 538,479 patients showed that renal impairment is an independent risk factor for thromboembolic events (relative risk of 1.62) and postulated that it should be added to the existing risk scores [26]. In our study, the $\mathrm{CHA}_{2} \mathrm{DS}_{2}$-VASc-RAF scale, taking into account the presence of eGFR $<56 \mathrm{ml} / \mathrm{min} / 1.73 \mathrm{~m}^{2}$, was the best predictor of LAAT in patients treated with either NOAC.

Our study demonstrated that LAAT would be detectable even in patients undergoing NOAC therapy. It might suggest that TOE should be performed in all patients with AF before electrical cardioversion or catheter ablation; however, the limitations of these invasive procedures, their potential side effects, and the personnel and equipment limitations of centres performing these procedures are known. The European Heart Rhythm Association (EHRA) conducted a survey in 54 centres to examine contemporary clinical practice regarding preprocedural diagnostic work-up in AF patients; only 6 centres $(12 \%)$ routinely performed TOE prior to left atrial procedures, regardless of the type or duration of $\mathrm{AF}$ [27]. Therefore, we are constantly looking for predictors to identify patients treated with NOAC who have a high risk of LAAT and for whom TOE is necessary. Based on the results of our study, patients treated with dabigatran who have nonparoxysmal AF, heart failure, or eGFR $<60 \mathrm{ml} / \mathrm{min} / 1.73 \mathrm{~m}^{2}$ and patients treated with rivaroxaban who have non-paroxysmal AF or heart failure should undergo TOE examination before electrical cardioversion or catheter ablation because they are at an increased risk of LAAT. 
4.1. Study Limitations. While investigating predisposing factors for LAAT formation in AF patients, attempts were made to identify factors predisposing to thromboembolic complications. In AF patients, the LAA is the most common source of embolism; so, the presence of LAAT can be considered a predisposing factor for thromboembolic complications. A limitation of the study is its retrospective nature; data such as detailed echocardiographic data (e.g., LAAV and EF) were not available for all subjects; therefore, they were not included in the multivariate analysis. The number of patients treated with apixaban was too small to be included in the analysis. Another limitation was the inability to determine the AF burden; the duration of arrhythmia in the subjects was unknown, which did not allow us to distinguish between persistent and long-standing persistent AF.

\section{Conclusions}

Despite consistent anticoagulant therapy, LAAT was diagnosed in AF patients and occurred with the same frequency in those treated with dabigatran and rivaroxaban. Periprocedural TOE should be performed in all patients with non-paroxysmal $\mathrm{AF}$ and heart failure and in those with eGFR $<60 \mathrm{ml} / \mathrm{min} / 1.73 \mathrm{~m}^{2}$ if they are being treated with dabigatran. The new $\mathrm{CHA}_{2} \mathrm{DS}_{2^{-}}$ VASc-RAF scale had the highest predictive value for LAAT in the entire study group. Its use is worth considering in patients with AF treated with a NOAC who are to undergo TOE prior to electrical cardioversion or catheter ablation.

\section{Data Availability}

The source data used to support the findings of this study are available from the corresponding author upon request.

\section{Conflicts of Interest}

Iwona Gorczyca participated in paid lectures for Bayer and Boehringer Ingelheim. Agnieszka Kapłon-Cieślicka and Krzysztof J. Filipiak participated in paid lectures for Bayer, Boehringer Ingelheim, MSD, and Pfizer. Grzegorz Opolski and Beata Wożakowska-Kapłon participated in paid lectures for Bayer, Boehringer Ingelheim, and Pfizer. All other authors declare that they have no conflicts of interest.

\section{Acknowledgments}

The authors would like to acknowledge that the project was financed under the program of the Minister of Science and Higher Education called "Regional Initiative of Excellence" in the years 2019-2022, project no. 024/RID/2018/19, and the amount of financing is 11999000,00 PLN.

\section{References}

[1] G. Y. H. Lip, B. Freedman, R. De Caterina, and T. S. Potpara, "Stroke prevention in atrial fibrillation: past, present and future," Thrombosis and Haemostasis, vol. 117, no. 7, pp. 1230-1239, 2017.

[2] A. Bukowska, M. Hammwöhner, D. Corradi, W. Mahardhika, and A. Goette, "Atrial thrombogenesis in atrial fibrillation,"
Herzschrittmachertherapie + Elektrophysiologie, vol. 29, no. 1, pp. 76-83, 2018.

[3] P. Kirchhof, S. Benussi, D. Kotecha et al., "ESC Guidelines for the management of atrial fibrillation developed in collaboration with EACTS," Europace, vol. 18, no. 11, pp. 1609-1678, 2016.

[4] A. L. Klein, R. A. Grimm, R. D. Murray et al., "Use of transesophageal echocardiography to guide cardioversion in patients with atrial fibrillation," The New England Journal of Medicine, vol. 344, no. 19, pp. 1411-1420, 2017.

[5] A. Z. Arnold, M. J. Mick, R. P. Mazurek, F. D. Loop, and R. G. Trohman, "Role of prophylactic anticoagulation for direct current cardioversion in patients with atrial fibrillation or atrial flutter," Journal of the American College of Cardiology, vol. 19, no. 4, pp. 851-855, 1992.

[6] S. Reers, G. Karanatsios, M. Borowski et al., "Frequency of atrial thrombus formation in patients with atrial fibrillation under treatment with non-vitamin $\mathrm{K}$ oral anticoagulants in comparison to vitamin $\mathrm{K}$ antagonists: a systematic review and meta-analysis," European Journal of Medical Research, vol. 23, no. 1, p. 49, 2018.

[7] J. W. McCready, L. Nunn, P. D. Lambiase et al., "Incidence of left atrial thrombus prior to atrial fibrillation ablation: is preprocedural transoesophageal echocardiography mandatory?" Europace, vol. 12, no. 7, pp. 927-932, 2010.

[8] K. Kosmalska, M. Rzyman, P. Miękus et al., "Usefulness of transesophageal echocardiography before cardioversion in atrial arrhythmias," Journal of Cardiology, 2019.

[9] E. Bertaglia, M. Anselmino, A. Zorzi et al., "NOACs and atrial fibrillation: incidence and predictors of left atrial thrombus in the real world," International Journal of Cardiology, vol. 249, no. 15, pp. 179-183, 2017.

[10] S. Schulman, "Advantages and limitations of the new anticoagulants," Journal of Internal Medicine, vol. 275, no. 1, pp. 1-11, 2017.

[11] B. F. Gage, A. D. Waterman, W. Shannon, M. Boechler, M. W. Rich, and M. J. Radford, "Validation of clinical classification schemes for predicting stroke," JAMA, vol. 285, no. 22, pp. 2864-2870, 2001.

[12] G. Y. H. Lip and J. L. Halperin, "Improving stroke risk stratification in atrial fibrillation," The American Journal of Medicine, vol. 123, no. 6, pp. 484-488, 2010.

[13] J. P. Piccini, S. R. Stevens, Y. Chang et al., "Renal dysfunction as a predictor of stroke and systemic embolism in patients with nonvalvular atrial fibrillation," Circulation, vol. 127, no. 2, pp. 224-232, 2013.

[14] A. Kapłon-Cieślicka, M. Budnik, M. Gawałko et al., "Atrial fibrillation type and renal dysfunction as important predictors of left atrial thrombus," Heart, vol. 105, no. 17, pp. 1310-1315, 2019.

[15] M. Wu, J. Gabriels, M. Khan et al., "Left atrial thrombus and dense spontaneous echocardiographic contrast in patients on continuous direct oral anticoagulant therapy undergoing catheter ablation of atrial fibrillation: comparison of dabigatran, rivaroxaban, and apixaban," Heart Rhythm, vol. 15, no. 4, pp. 496-502, 2018.

[16] R. Cappato, M. D. Ezekowitz, A. L. Klein et al., "Rivaroxaban vs. vitamin $\mathrm{K}$ antagonists for cardioversion in atrial fibrillation," European Heart Journal, vol. 35, no. 47, pp. 3346-3355, 2014.

[17] S. J. Connolly, M. D. Ezekowitz, S. Yusuf et al., "Dabigatran versus warfarin in patients with atrial fibrillation," New England Journal of Medicine, vol. 361, no. 12, pp. 1139-1151, 2009.

[18] M. Gawałko, A. Kapłon-Cieślicka, M. Budnik et al., "Comparison of different oral anticoagulant regimens in patients with atrial fibrillation undergoing ablation or cardioversion," 
Polish Archives of Internal Medicine, vol. 127, no. 12, pp. 823-831, 2017.

[19] A. G. Bejinariu, D. U. Härtel, J. Brockmeier, R. Oeckinghaus, A. Herzer, and U. Tebbe, "Left atrial thrombi and spontaneous echo contrast in patients with atrial fibrillation," Herz, vol. 41, no. 8, pp. 706-714, 2016.

[20] R. M. Melduni, B. J. Gersh, W. E. Wysokinski et al., "Real-time pathophysiologic correlates of left atrial appendage thrombus in patients who underwent transesophageal-guided electrical cardioversion for atrial fibrillation," The American Journal of Cardiology, vol. 121, no. 12, pp. 1540-1547, 2018.

[21] J. Barysiene, A. Zebrauskaite, D. Petrikonyte D et al., "Findings of transoesophageal echocardiogram in appropriately anticoagulated patients with persistent atrial fibrillation prior to planned cardioversion," BMC Cardiovascular Disorders, vol. 17, no. 1, p. 67, 2017.

[22] D. Frenkel, S. A. D'Amato, M. Al-Kazaz et al., "Prevalence of left atrial thrombus detection by transesophageal echocardiography," JACC: Clinical Electrophysiology, vol. 2, no. 3, pp. 295-303, 2016.

[23] M. Kawabata, M. Goya, T. Sasaki et al., "Left atrial appendage thrombi formation in Japanese non-valvular atrial fibrillation patients during anticoagulation therapy," Circulation Journal, vol. 81, no. 5, pp. 645-651, 2017.

[24] A. N. Ganesan, D. P. Chew, T. Hartshorne et al., "The impact of atrial fibrillation type on the risk of thromboembolism, mortality, and bleeding: a systematic review and meta-analysis," European Heart Journal, vol. 37, no. 20, pp. 1591-1602, 2016.

[25] M. N. Di Minno, P. Ambrosino, A. Dello Russo A et al., "Prevalence of left atrial thrombus in patients with nonvalvular atrial fibrillation. A systematic review and metaanalysis of the literature," Thromb Haemost, vol. 115, no. 3, pp. 663-667, 2016.

[26] W. T. Zeng, X. T. Sun, K. Tang et al., "Risk of thromboembolic events in atrial fibrillation with chronic kidney disease," Stroke, vol. 46, no. 1, pp. 157-163, 2015.

[27] M. M. Farkowski, K. Jubele, F. Marín et al., "Diagnosis and management of left atrial appendage thrombus in patients with atrial fibrillation undergoing cardioversion or percutaneous left atrial procedures: results of the European Heart Rhythm Association survey," EP Europace, vol. 22, no. 1, pp. 162-169, 2020. 